\title{
3D XCT Mesostructure Characterization and Image-Based Discrete Element (DE) Modelling of Failure Patterns in Coal Gangue Particles (CGPs)
}

\author{
K. H. Zheng $\mathbb{D}^{1},{ }^{1}$ B. J. Qiu $\left(\mathbb{D},{ }^{2}\right.$ J. P. Li, ${ }^{3}$ and K. D. Gao ${ }^{4}{ }^{4}$ \\ ${ }^{1}$ College of Civil Engineering and Architecture, Zhejiang University, Hangzhou 310058, China \\ ${ }^{2}$ Center for Hypergravity Experimental and Interdisciplinary Research, Zhejiang University, Hangzhou 310058, China \\ ${ }^{3}$ College of Mechanical and Electrical Engineering, China University of Mining and Technology, Xuzhou 221116, China \\ ${ }^{4}$ Shandong Province Key Laboratory of Mine Mechanical Engineering, Shandong University of Science \& Technology, \\ Qingdao, China
}

Correspondence should be addressed to B. J. Qiu; qbj@zju.edu.cn

Received 12 July 2019; Revised 24 October 2019; Accepted 29 October 2019; Published 22 November 2019

Academic Editor: Michele Scarpiniti

Copyright ( $) 2019$ K. H. Zheng et al. This is an open access article distributed under the Creative Commons Attribution License, which permits unrestricted use, distribution, and reproduction in any medium, provided the original work is properly cited.

\begin{abstract}
The paper presents an application of milli- and micro-XCT to mesostructure characterization of CGPs and failure patterns analysis using dynamic impact simulations. In this study, XCT scanning experiments are firstly conducted on CGPs, followed by a series of image analyses with qualitative results. Then, the $3 \mathrm{D}$ mesomorphological parameters and internal composition of individual particles are quantitatively characterized. Finally, dynamic impact loading in $y$-axis direction is modelled to investigate the $3 \mathrm{D}$ mesostructure and different impact velocity effects on failure patterns of individual particles. The studies show that the mesomorphological parameters present different distribution characteristics in individual CGPs. The approximate location of gangue phase is the key parameter that should be taken into account to study failure patterns as well as fracture mechanism of the heterogeneous rock materials. The XCT image-based numerical model proved to be an effective tool that gives insights into the mesodeformation mechanisms of heterogeneous coal rock (HCR) undergoing dynamic impact failure behavior.
\end{abstract}

\section{Introduction}

Multiscale experiments and modelling of multiphase mineral materials, such as coal, gangue, and various composite materials, are of critical importance for the detailed analysis of the mesostructure and failure patterns of coal ores. In general, the crushing performance for CGPs depends on the statistical characteristics of geometric shape and mesostructures, such as internal composition distribution, phase continuity, and initial damage. Currently, research studies on the characterization of morphological and mechanical properties of individual CGPs are mainly based on experimental analysis [1-4]. Although the experimental method could provide statistic results, unavoidable sampling errors are widely existed by using experimental analysis. Especially, the geometric shape and mesostructure characteristics of individual particles are the determinant of their fragmentation characteristics. Therefore, it is important to link the crushing performances for CGPs to their complex mesostructures.

Qualitative and quantitative analyses of the mesostructure characteristics and mesocrack evolution mechanism will lead to more accurate descriptions and thus improvement to the crushing process [5]. Two-dimensional mesoscale finite element models with realistic mesostructure of concrete are developed using micro-XCT images to simulate complex nonlinear fracture $[6,7]$. The microstructural characteristics of asphalt mixture under different compaction powers are investigated [8,9]. Physical and hydraulic properties of a coastal sand aquifer were derived using micro- and macro-X-ray computed tomography (XCT) techniques $[10,11]$. The copper and iron ores were crushed using a jaw crusher first, and then the products were evaluated for particle damage and copper grain exposure by $\mathrm{X}$-ray computed tomography $[12,13]$. A finite element 
model of coke was generated using micro-X-ray CT, and coke strength was numerically evaluated using its microstructure [14]. The principle, the advantages, and the limitations of XCT itself are presented, together with an overview of some current applications of micro-CT in geomaterials [15-19].

Characterization of multiphase mineral using XCT techniques would be extremely helpful for an improved understanding of coal particle crushing processes. Novel image processing techniques combined with stochastic analysis are also used to analyze the $3 \mathrm{D}$ images of the porous structure of coal [20]. The fraction of mineral exposed and the ultimate recovery for a given particle size distribution can be established by X-ray microtomography [21]. The characterization of individual multiphase particle has been studied by Arias and Miller [22], and several effective algorithms were also proposed by Miller and Lin to study the mesostructure of different minerals [23-25]. From the abovementioned analysis, most of the studies have investigated the mesostructure of individual particles, but only a small number of coal gangue samples have been studied by the very limited XCT scanning studies and the results are inconclusive. Besides, the inclusions in individual particles are usually assumed to be a polygonal irregular body, which has huge difference with the real internal mesostructure in individual CGPs. This may also lead to theoretical and numerical models that cannot study the fracture characteristics of individual CGPs inaccurately.

In this study, we aim to improve the understanding of mesomorphologies of CGPs (such as geometric shape, 3D mesomorphological parameters, and internal composition) and their correlations with loading conditions, combining the micro-XCT scanning tests and numerical simulations. A large number of raw coal gangue samples with different internal mesostructures are examined in detail using different image processing techniques. A reliable $3 \mathrm{D}$ mesoscopic numerical approach (the image-based DE model) is also proposed to study $3 \mathrm{D}$ fracture evolution process of HCR under different impact velocities at the mesolevel.

\section{XCT Image Acquisition, Processing, and Analysis}

2.1. XCT Scanning. The packed crushed CGPs with particle size range from $10 \sim 100 \mathrm{~mm}$, which were provided by Dengfeng mining in China, are simply packed in a cylindrical container (Figure 1(a)) and scanned on Philips milliCT equipment (Figure 1(b)). The 3D image data obtained from Philips milli-CT equipment contain 901 projections of $512 \times 512$ pixels with a voxel resolution of $470 \mu \mathrm{m}$. Another micro-XCT-400 machine with much higher resolution (Figure 1(c)) is used to scan the fine particles with size 1 5 mm [26]. Figures 1(d) and 1(e) show the sample container with a diameter of $40 \mathrm{~mm}$ and $5 \mathrm{~mm}$, respectively. These fine samples are tightly packed in the containers to obtain higher quality images with voxel size $32 \mu \mathrm{m}$ for subsequent data analyses.

Figure 2 shows the variation of CT values of the sectioned $2 \mathrm{D}$ images along the probeline $\mathrm{AB}$. The sensitivity to location was examined by using line probe to verify that most of CGPs are multiphase particles. As shown in Figure 2, different mineral phases are clearly distinguished in different grey scale levels. The dark grey, light grey, and light white regions represent sections of coal, gangue, and pyrite mineral grains, respectively. These raw CT images are then processed and analyzed to acquire the quantitative information to characterize the $3 \mathrm{D}$ mesostructure of individual CGPs.

2.2. CT Image Processing and Segmentation. A series of image processing procedures, including image denosing and image enhancing, should be applied to original CT images that aim to increase the precision of subsequent processing algorithms. It is clear that segmentation is one of the most critical steps to obtain accurate morphological parameters in the process of boundary regions between particle phases and cracks. For quantitatively analyzing particle damage accurately, segmentation of the particle phases and cracks from the background is accomplished by the conventional threshold algorithm or feature-based classification algorithm [27, 28], depending on the different particle phases and crack characteristics in particles. The conventional threshold segmentation algorithm works well for most coarse coal gangue particles, due to the high-contrast boundaries in internal particles and sufficient scanning resolutions. However, for a fine particle image with a scale parameter (i.e., the ratio of particle size and voxel size [28]) less than 30 (Figure 3(a)) or artificial CT images (Figure $3(\mathrm{~d})$ ), the conventional threshold often provides unsatisfactory results because of some noises similar to our interest regions and the insufficient contrast boundaries, as shown in Figures 3(b) and 3(e), where the segmented image is not satisfactory for detailed analysis of internal compositions and internal damages. Correctly identifying internal composition and internal damage in particles by XCT can be challenging, due to insufficient contrast boundaries or small characteristics near the resolution limit.

In this regard, a feature-based classification method, which not only takes image intensities but also a series of image features into account to identify particle boundaries [29], is proposed to extract useful features to realize better segmentation effect [30]. Firstly, red and green lines are annotated as the training set of the particle phase and background, respectively (Figure 4(a)). Then, the random classifier was trained from the selected data, and the particles' extraction image and background image are shown in Figures 4(b) and 4(c), respectively. Finally, the improved segmentation results of the small-scale image and artificial CT image are shown in Figures 3(c) and 3(f), respectively. It proved that the feature-based classification method is a powerful tool to improve the accuracy of the specific image.

Similarly, different mineral phases and background regions are selected as a training set to segment different mineral phases from the background (air). The improved segmentation results for the small-scale image and artificial CT image shown in Figure 5 are satisfactory for subsequent segmentation process and for detailed quantitative analysis 


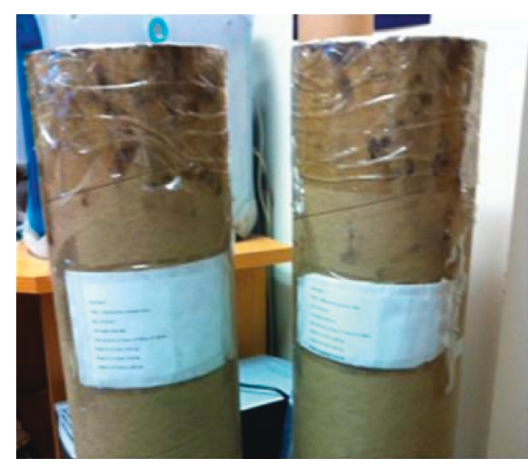

(a)

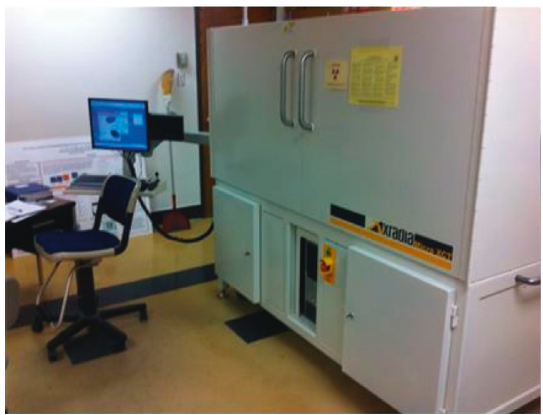

(c)

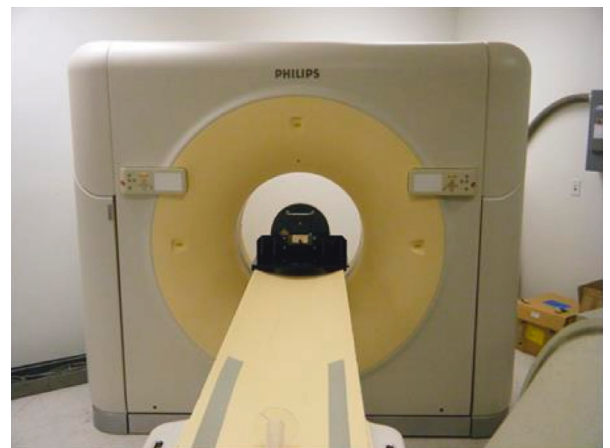

(b)

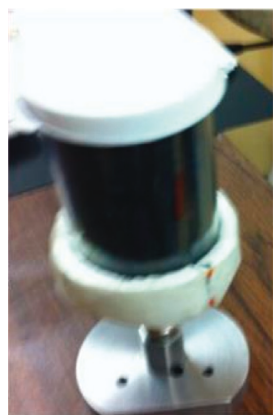

(d)

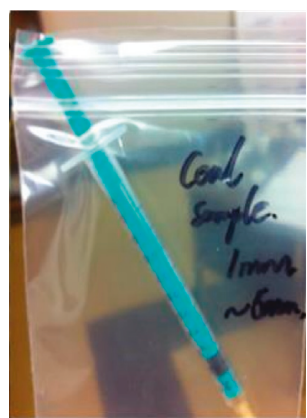

(e)

FIgURE 1: CT scanning facilities used (a) presents the raw coal gangue samples; (b) presents the Philips Tomoscan 60/TX CT scanner for raw samples; (c) presents the micro-XCT-400 scanner for crushed particles; (d) presents the $40 \mathrm{~mm}$ diameter container for fine CGPs samples; and (e) presents the $5 \mathrm{~mm}$ diameter container for fine CGPs.

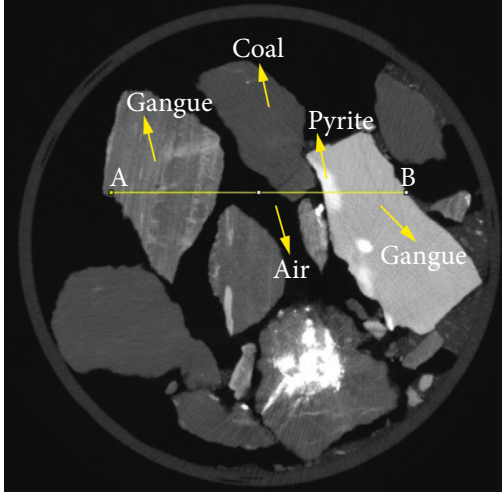

(a)

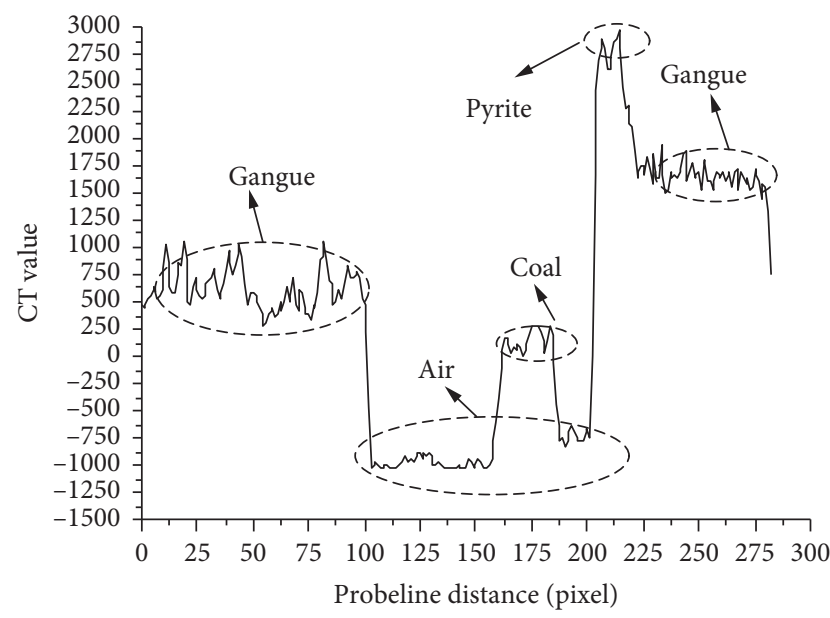

(b)

FIGURE 2: Variation of CT values of the sectioned 2D images along the probeline $\mathrm{AB}$ cutting are shown to reveal detailed information of the packed samples. This figure (a) presents the line-probe path $\mathrm{AB}$ and (b) presents the variation of $\mathrm{CT}$ values along $\mathrm{AB}$.

of multiphase particles. Table 1 shows the comparative results of composite analysis for different algorithms. As shown in Table 1, the feature-based segmentation algorithm has been found to perform very well in the analysis of smallscale images of CGPs. In fact, for the small-scale image of CGPs (scale parameter 28), the precision difference between the two algorithms can reach to $28.08 \%$ when traditional image segmentation was replaced by feature-based segmentation. For the artificial image of CGPs (scale parameter
84), the range of error was $6.34 \%$ when traditional image segmentation was replaced by feature-based segmentation.

\section{3D Individual Particle Characterization Using XCT}

3.1. Internal Composition Characterization of Individual CGPs. Intensity histograms of the randomly selected ten particles are shown in Figure 6. It is clear from Figure 6 that 


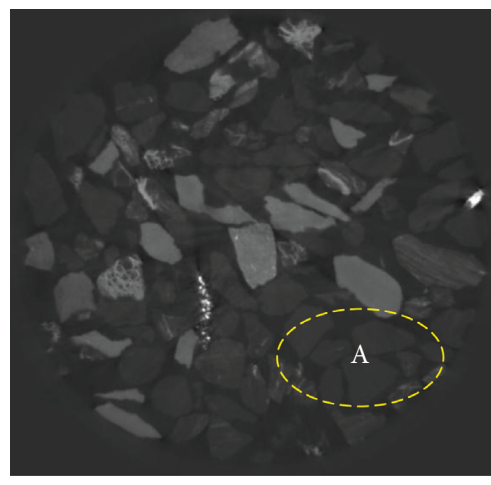

(a)

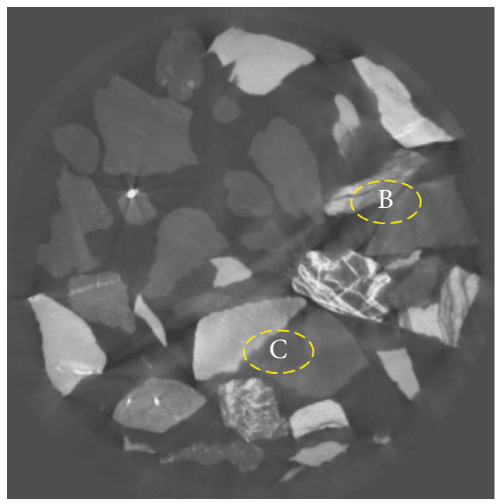

(d)

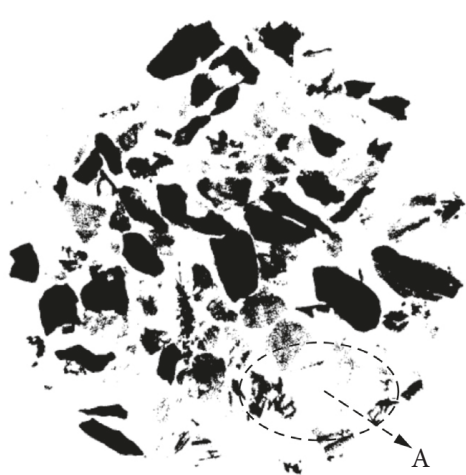

(b)

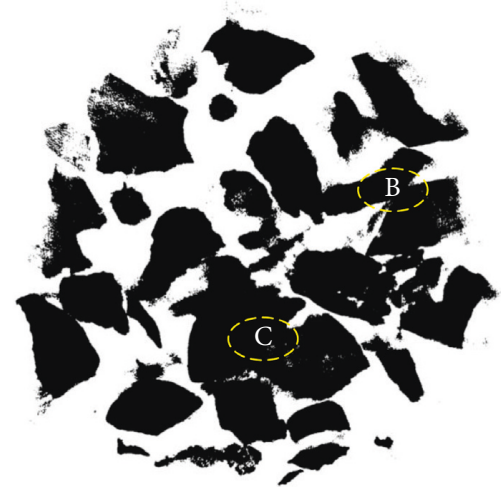

(e)

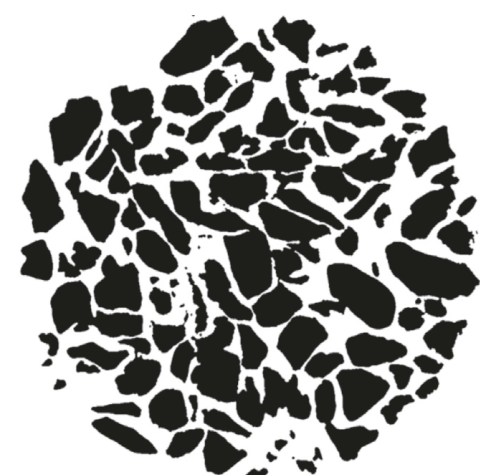

(c)

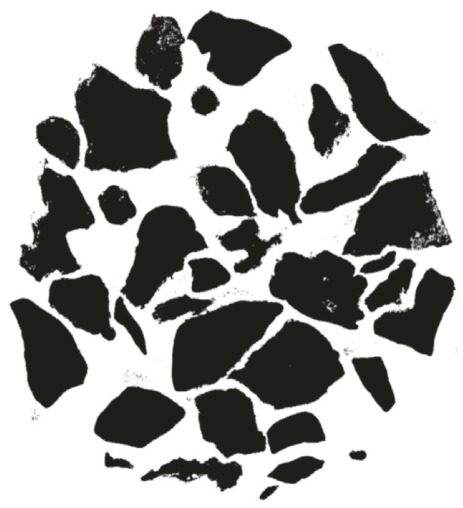

(f)

FIGURE 3: Segmentation results of small-scale CT image and the artificial CT image-based different segmentation algorithms. In this figure, (a) and (d) presents the original small-scale image and artificial image, respectively; (b) and (e) presents the segmentation results based on the conventional threshold algorithm; (c) and (f) presents the improved segmentation results based on the feature-based segmentation algorithm.

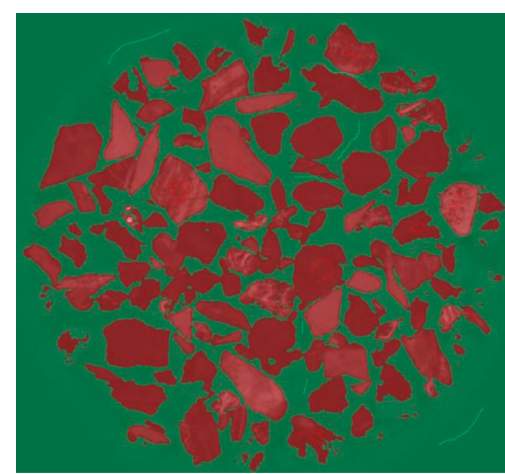

(a)

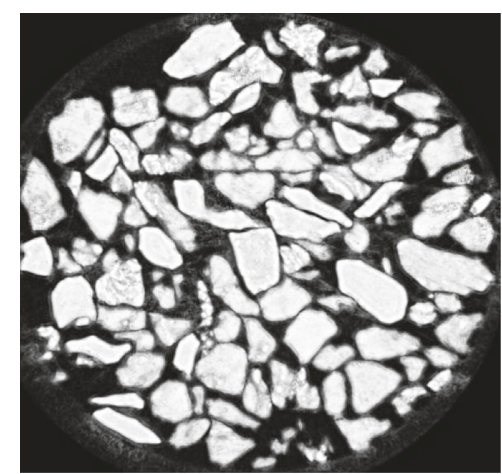

(b)

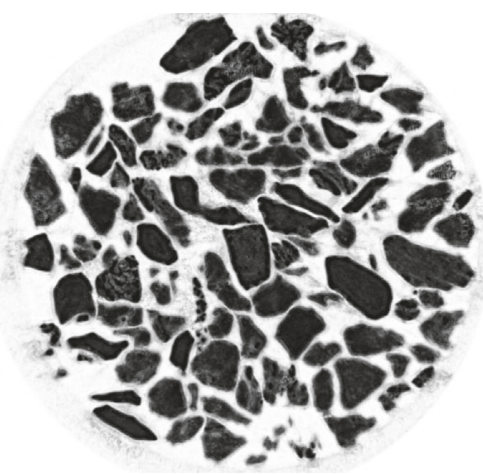

(c)

FIgURE 4: Training of small-scale CT images using trainable Weka segmentation tool. This figure (a) presents the segmented image after applying the forest classifier; (b) presents foreground (particle); and (c) presents background extraction.

the intensity characteristics of individual particles show different distribution characteristics, and a higher density mineral phase has a higher intensity value. The intensityfrequency distribution curve of the multiphase particle shows multipeak characteristics. Further analysis validated that individual CGPs can be divided into three types: singlephase particle, biphase particle, and triphase particle. In this regard, three typical particles were selected and their intensity histograms were determined, respectively, to illustrate the difference of individual particles. Frequency distribution curves and 3D volume-rendering images are shown in Figures 7-9, respectively.

Intensity-frequency distribution curves and $3 \mathrm{D}$ volumerendering images of the selected single-phase particles are shown in Figures 7(a) and 7(b), respectively. It is clear that the intensity histograms of individual CGPs are fitted well using the normal distribution model. The coal intensity histogram varies from 0 to 450 , and its peak value is 315 . For 


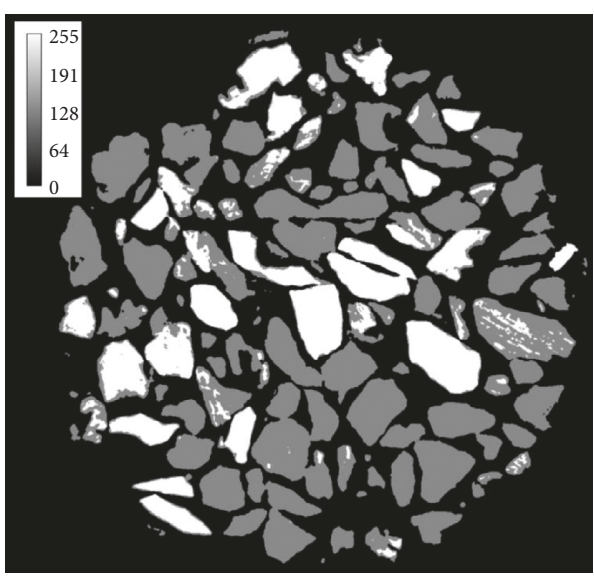

(a)

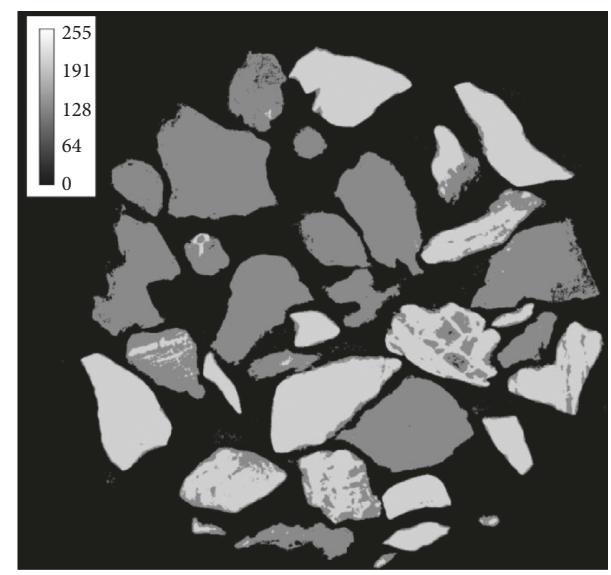

(b)

Figure 5: Segmentation results for the small-scale CT image and the artificial image based on the feature-based algorithm. This figure (a) presents the small-scale CT image and (b) presents the artificial image.

TABLE 1: Comparison for segmentation and validation results of CGPs.

\begin{tabular}{|c|c|c|c|c|c|c|}
\hline \multirow{2}{*}{$\begin{array}{l}\text { Sample } \\
\text { size } \\
(\mathrm{mm})\end{array}$} & \multirow{2}{*}{$\begin{array}{l}\text { Resolution } \\
\quad(\mu \mathrm{m})\end{array}$} & \multirow{2}{*}{$\begin{array}{c}\text { Scale } \\
\text { parameter }\end{array}$} & \multirow{2}{*}{$\begin{array}{l}\text { Segmentation } \\
\text { algorithm }\end{array}$} & \multicolumn{2}{|c|}{$\begin{array}{l}\text { Composition } \\
\text { analysis (\%) }\end{array}$} & \multirow{2}{*}{$\begin{array}{c}\text { Error } \\
(\%)\end{array}$} \\
\hline & & & & Coal & Gangue & \\
\hline \multirow{2}{*}{$1 \sim 2$} & 35.35 & 28 & Thresholding & 62.79 & 37.21 & \multirow{2}{*}{28.08} \\
\hline & 35.35 & 28 & Feature-based & 73.24 & 26.76 & \\
\hline \multirow{2}{*}{$3 \sim 5$} & 35.35 & 84 & Thresholding & 56.68 & 43.32 & \multirow{2}{*}{6.34} \\
\hline & 35.35 & 84 & Feature-based & 59.43 & 40.57 & \\
\hline
\end{tabular}

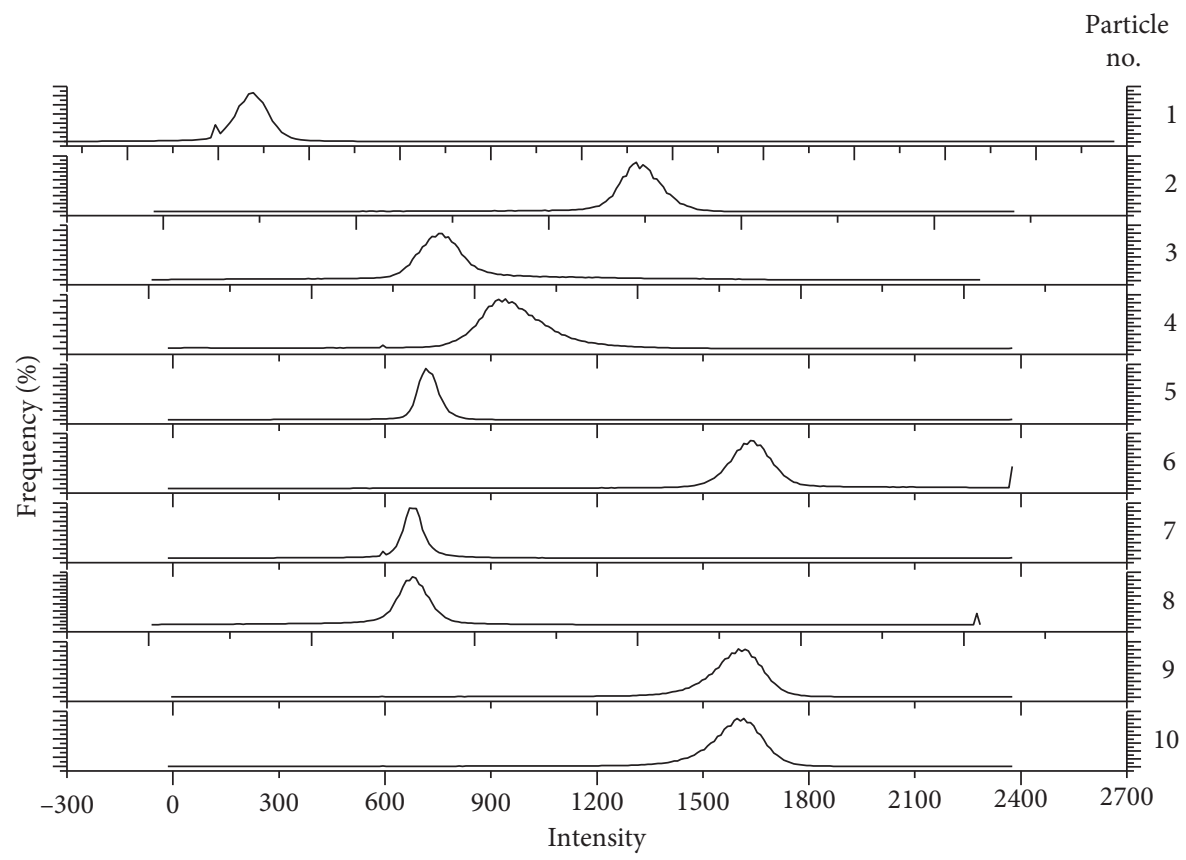

FIGURE 6: Intensity histograms of the randomly selected ten CGPs.

a gangue particle, the intensity histogram varies from 1200 to 2400 , and its peak value is 1763 . The intensity histogram of the gangue particle has only one peak, which further indicates that the selected gangue particle is a single-phase mineral. It can also be concluded from Figure 7 that big difference exists between the intensity histogram distribution of coal and gangue, which can be distinguished from the intensity histogram easily.

Figure 8 shows the results of the intensity-frequency distribution curve and the 3D volume-rendering image of 


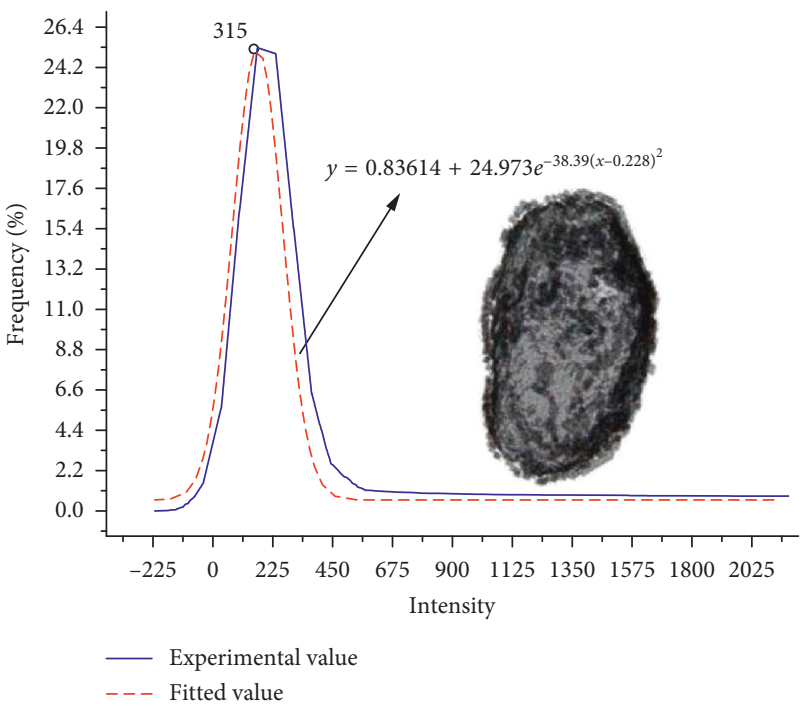

(a)

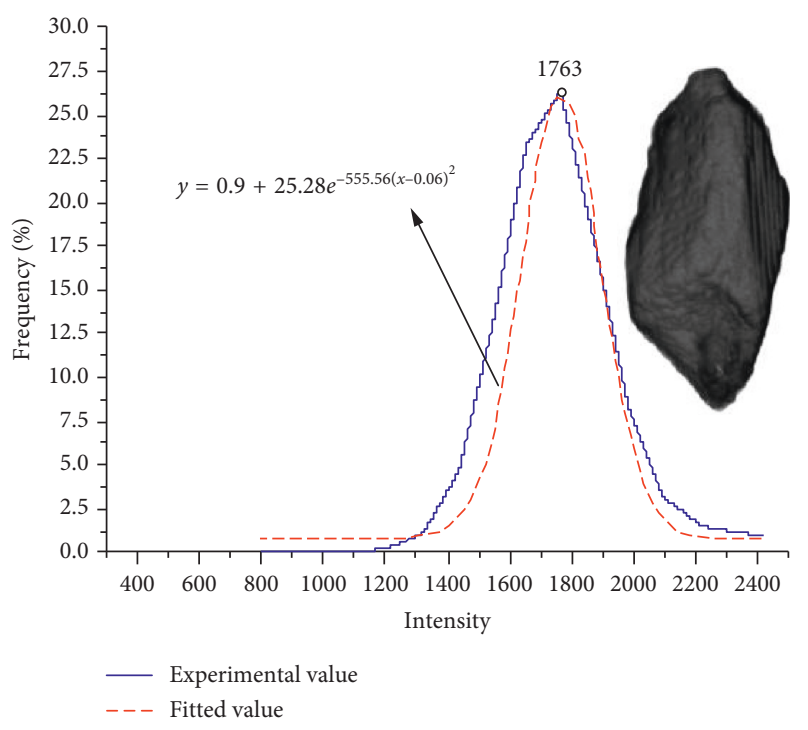

(b)

FIgURE 7: Intensity-frequency distribution curves and 3D volume-rendering images for the selected single-phase particles. This figure presents (a) the coal particle and (b) the gangue particle.

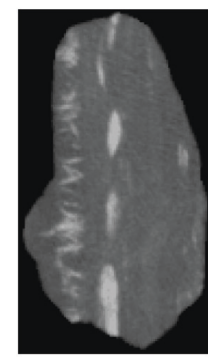

(a)

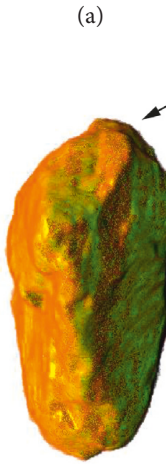

(b)
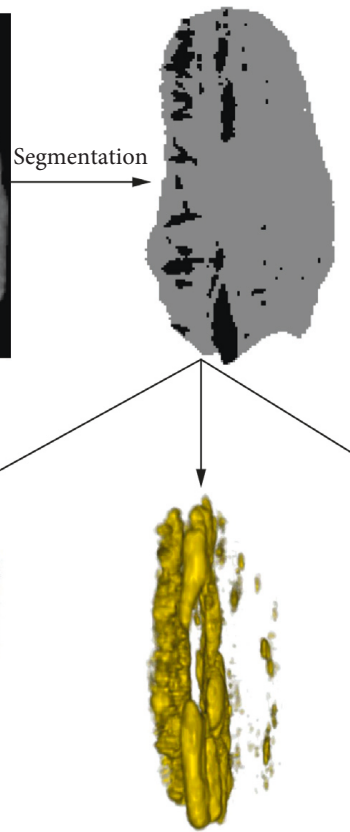

(c)

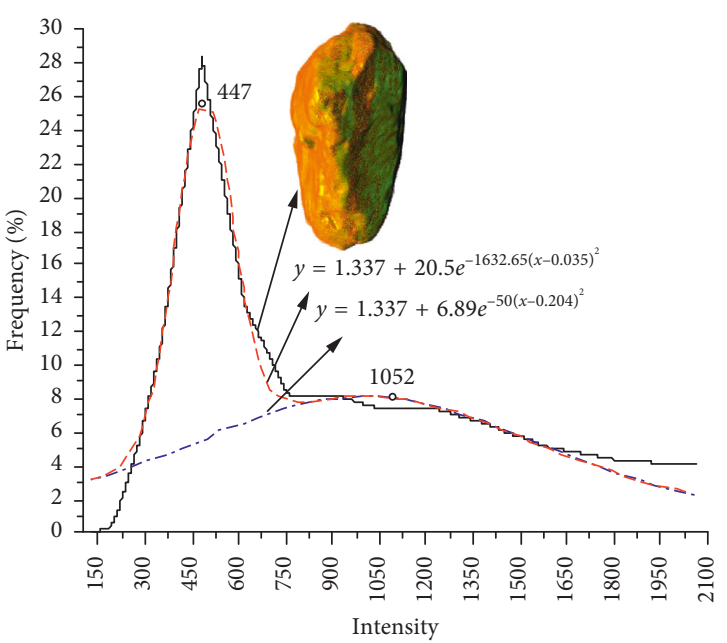

- Experimental value
-.-. Fitted value of gangue

--- Fitted value of coal

(e)

FIGURE 8: Intensity-frequency distribution curve and 3D volume-rendering image for the selected biphase particle. This figure presents (a) the original CT image; (b) the whole particle; (c) the gangue phase; (d) the coal phase; (e) the frequency distribution curve of intensity.

the selected biphase particles. As indicated from the curves shown in Figure 8, the intensity value varies from 100 to 2100 , and the frequency distribution curve of intensity has two peaks, which indicated that the selected particle is a biphase particle (the individual particles are composited by coal and gangue, respectively). The intensity histogram of biphase particle is analyzed through multinormal distribution. It can be seen that the experimental data fit well, relating the frequency distribution and the intensity values. Further analysis shows that the volume proportion distributions of coal and gangue are $82.91 \%$ and $17.09 \%$, respectively.

Figure 9 shows the intensity histogram and volume rendering of the selected triphase particle. The intensity histogram presents a trimodal distribution, and the intensity value varies from 120 to 3100 . The peak value of three phases can reach to 710,1500 , and 3078 , respectively. The volume proportion distributions of coal, gangue, and pyrite are $23.27 \%$, $41.58 \%$, and $35.15 \%$, respectively. 


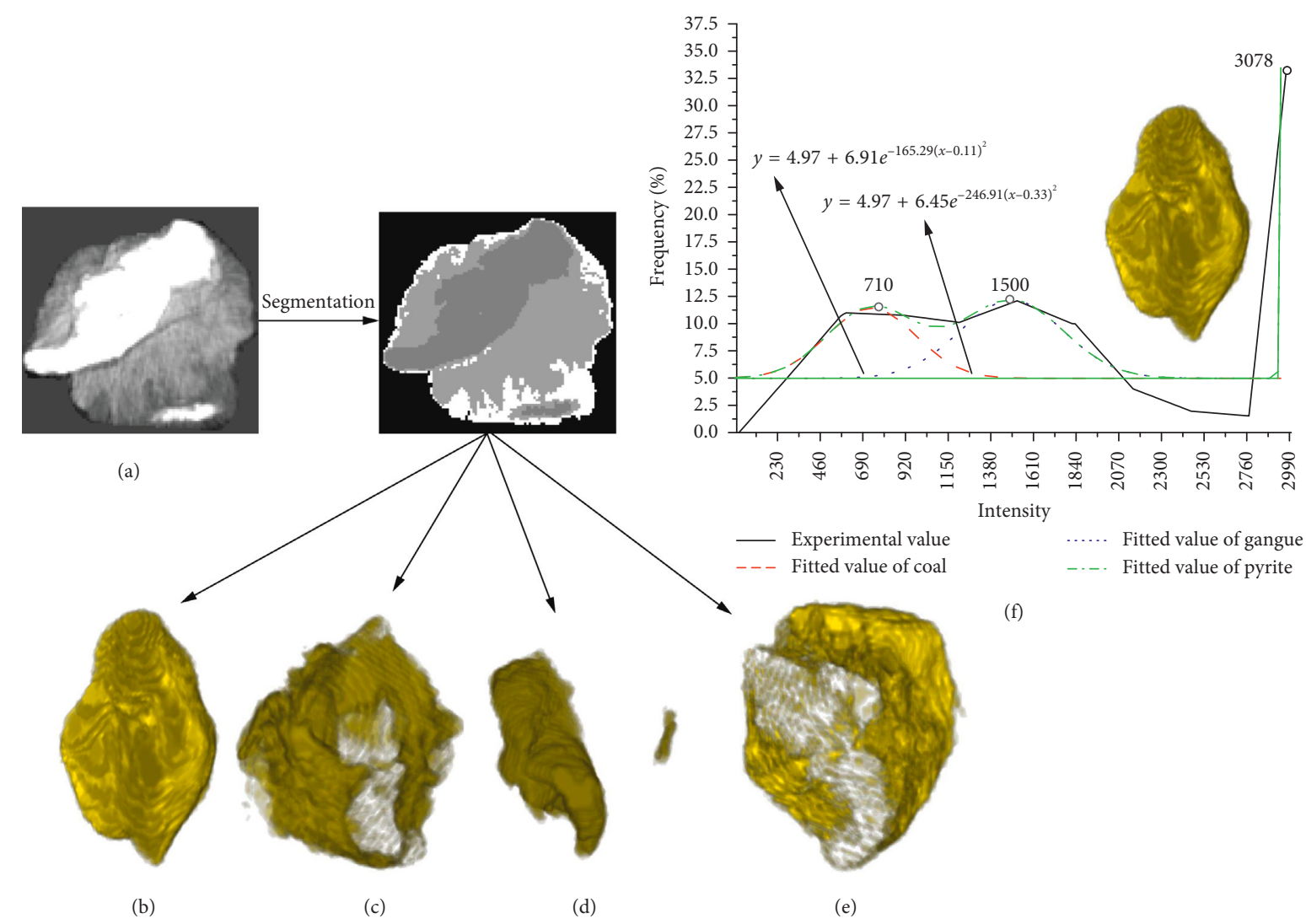

FiguRE 9: Intensity-frequency distribution curves and 3D volume-rendering image for the selected triphase particle. This figure presents (a) the original CT image; (b) the whole particle; (c) the gangue phase; (d) the pyrite phase; (e) the coal phase; (f) the frequency distribution curve of intensity.

3.2. Characterization of 3D Mesomorphological Parameters. In order to illustrate internal damage of the individual CGPs, the original CT image of the selected coal particle shown in Figure 10(a) is typically segmented and reconstructed (Figure 10(b)) from the packed particle bed. It is clear that cracks in different slices and internal damage can be clearly identified from original CT images. These raw coal CT images are processed using different segmentation algorithms to get the satisfied binary images shown in Figure 11.

As shown in Figure 11, the cracks shown in black are extracted in different slices, and the particle boundary is marked in grey color. The segmented CT images provide quantitative information to characterize internal damage of individual particles, and the quantitative analysis results can be seen in Table 2. The calculation indexes shown in Table 2 were described in [31-34]. It is clear that different mesomorphological parameters (crack number, length, width, perimeter, area, and angle) can be obtained in different slices. The variation tendency of the fracture ratio in different slices of the selected individual particle is shown in Figure 12. As shown in Figure 12, there are two peaks during slices 7 15 and 45 62, which indicates that fracture degree of the coal particle is relatively serious in these two parts. It is also clear from Figure 12 that different slices have different fracture ratios, which indicates that different damage degrees are existed in internal particles. Further 3D quantitative analysis showed that the fracture ratio can reach to $5.06 \%$.
From the abovementioned analysis, it proved that the mesostructure of individual CGPs can be qualitative and quantitative analyzed after loading (i.e., volume fractions, sizes, shapes, and spatial distribution of mineral phases). Due to the impact loading process always occurs within a few microseconds, the continuous investigations of the entire fracture process with the current XCT techniques is not workable for technical reasons yet. In this regard, the 3D numerical image-based DE model provides a feasible way to examine the mesostructure damage and fracture evolution, which is described in detail in the following section.

\section{XCT Image-Based DE Simulations}

4.1. 3D Image-Based DE Model Generation. A coal cube specimen of size $32 \mathrm{~mm}$ (Figure 13(a)) was cropped from raw coal 3D dataset of 16 bit float with 1372 slices. For each slices, there are $1720 \times 1771$ pixels of $32 \mu \mathrm{m}$ in $x \times y$ direction in the sampled image dataset. To reduce the data processing time, the $3 \mathrm{D}$ data size was reduced to $500 \mathrm{MB}$ for the $3 \mathrm{D}$ original dataset with the resolution also compressed from $32 \mu \mathrm{m}$ to $100 \mu \mathrm{m}$ using Avizo software. These raw compressed CT images are segmented to get the 3D mesomorphologies of HCR, and then reconstructed to get the 3D surface model. This is followed by Laplacian smoothing [35] (Figure 13(b)) and surface simplification [36] to get the simplified surface model (Figure 13(c)). As shown in 


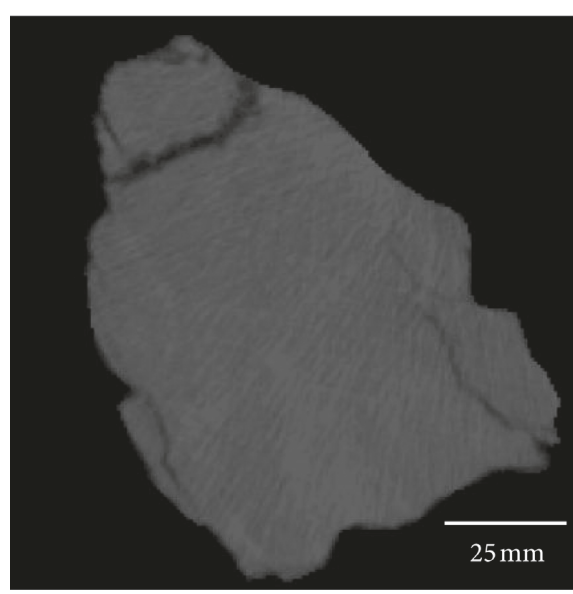

(a)

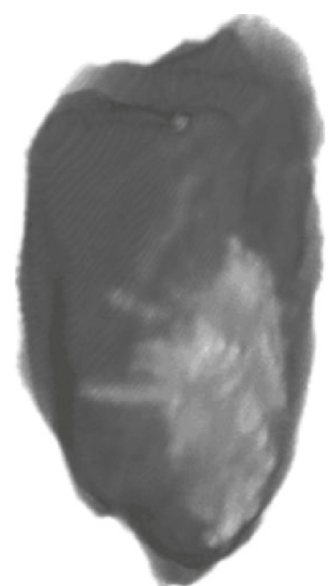

(b)

FIGURE 10: Original CT image and 3D volume-rendering image of the selected coal particle, respectively.

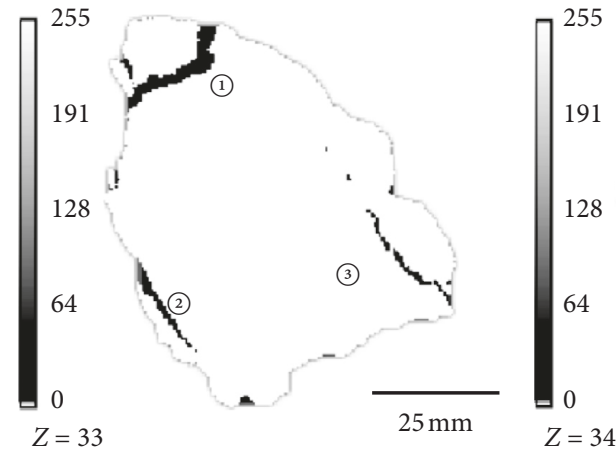

(a)

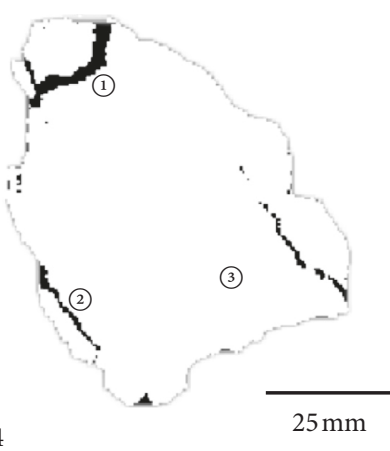

(b)

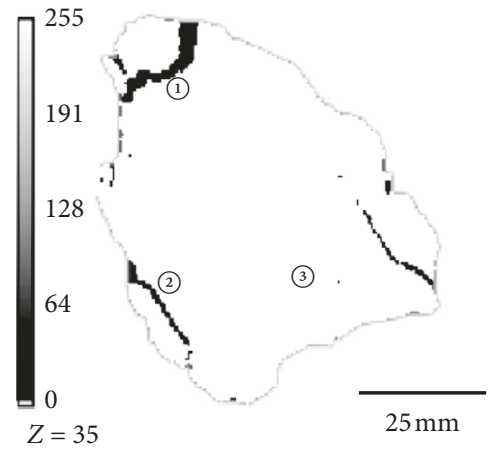

(c)

FIGURE 11: Slices of coal obtained from the CT image and the corresponding initial isolation of segmented cracks (black). Delineation of the particle boundary is shown in grey color.

TABLE 2: Quantitative analysis of coal internal cracks in the selected three slices.

\begin{tabular}{|c|c|c|c|c|c|c|}
\hline CT slice & Crack no. & Length $(\mathrm{mm})$ & Width $(\mathrm{mm})$ & Angle $\left({ }^{\circ}\right)$ & Perimeter $(\mathrm{mm})$ & Area $\left(\mathrm{mm}^{2}\right)$ \\
\hline & (1) & 23.887 & 3.427 & 43.363 & 25.92462 & 14.83195 \\
\hline \multirow[t]{3}{*}{$Z=33$} & (2) & 16.348 & 1.782 & 127.875 & 15.49665 & 9.063892 \\
\hline & (3) & 39.18 & 1.127 & 128.766 & 32.89973 & 19.05452 \\
\hline & (1) & 23.389 & 3.366 & 50.194 & 27.96137 & 15.75868 \\
\hline \multirow[t]{3}{*}{$Z=34$} & (2) & 16.724 & 0.841 & 129.611 & 17.42324 & 10.60892 \\
\hline & (3) & 34.354 & 0.644 & 129.898 & 37.1898 & 21.52674 \\
\hline & (1) & 23.489 & 3.187 & 48.576 & 55.11789 & 64.21975 \\
\hline \multirow[t]{2}{*}{$Z=35$} & (2) & 18.052 & 1.335 & 124.439 & 43.6024 & 55.31336 \\
\hline & (3) & 36.495 & 0.563 & 129.536 & 67.18277 & 81.56377 \\
\hline
\end{tabular}

Figure 13(c), there are 36386 triangles in the simplified surface model.

In the image-based DE modelling process, the total 91672 discrete elements (balls) with the radius $0.433 \mathrm{~mm}$ were put into the simplified surface model to generate the $3 \mathrm{D}$ DE model (Figure 13(d)). As shown in Figure 13(d), 77387 and 14285 balls were identified as coal and gangue clusters based on the shape of the coal phase and gangue phase, respectively. The followed procedure is the settlement of the balls until their total kinetic energy became insignificant.
In DEM analysis, the macroscale mechanical parameter, such as elastic modulus $E$, Poisson ratio $\mu$, and compressive strength $\sigma$, cannot be directly imposed into the numerical model. Therefore, it is critical to select appropriate mesoparameters for the numerical model that aims to represent the accurate macroscale mechanical behavior of HCR. The calibration approach is used to determine these appropriate mesoparameters, and the detailed calibration procedure $[37,38]$ has been demonstrated in Figure 14, which is described in detail as follows: 


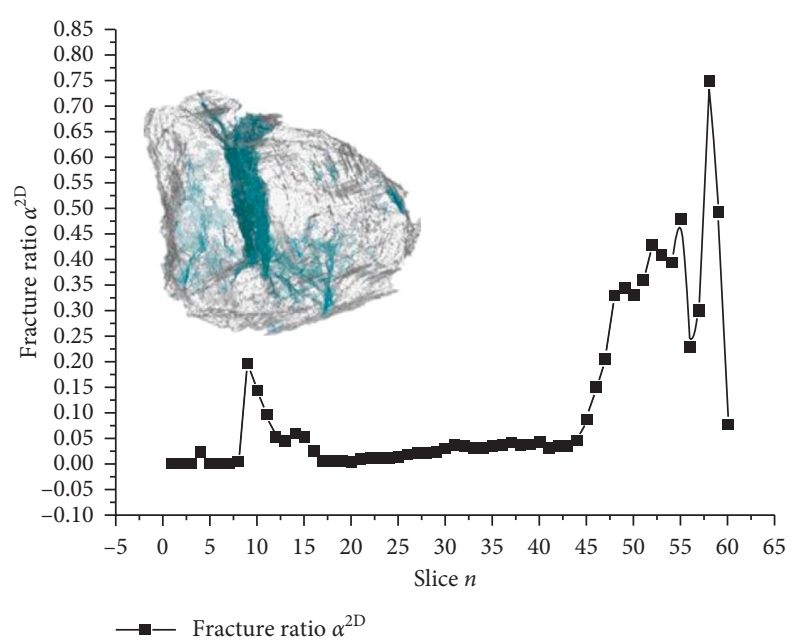

FiguRE 12: Variation tendency of fracture ratio in different slices of individual coal particles (the cracks are in blue and the coal gangue in grey).

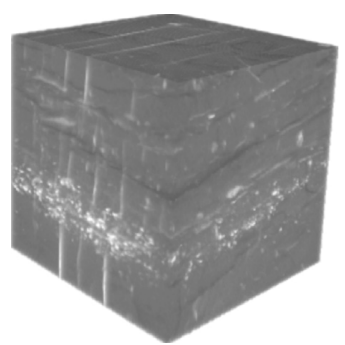

(a)

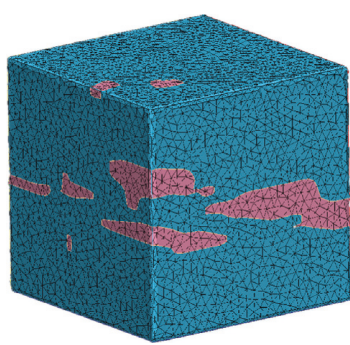

(b)

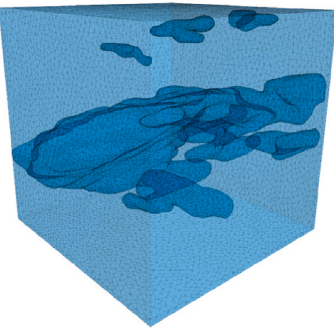

(c)

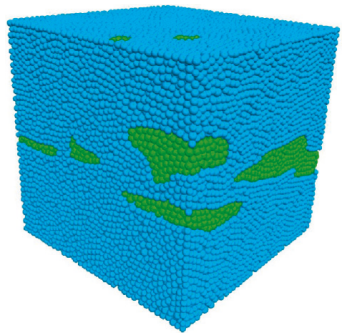

(d)

FIGURE 13: 3D DE model generate of HCR. This figure presents (a) the raw coal sample; (b) the smoothed surface model; (c) the simplified surface model; and (d) the 3D DE model of HCR.

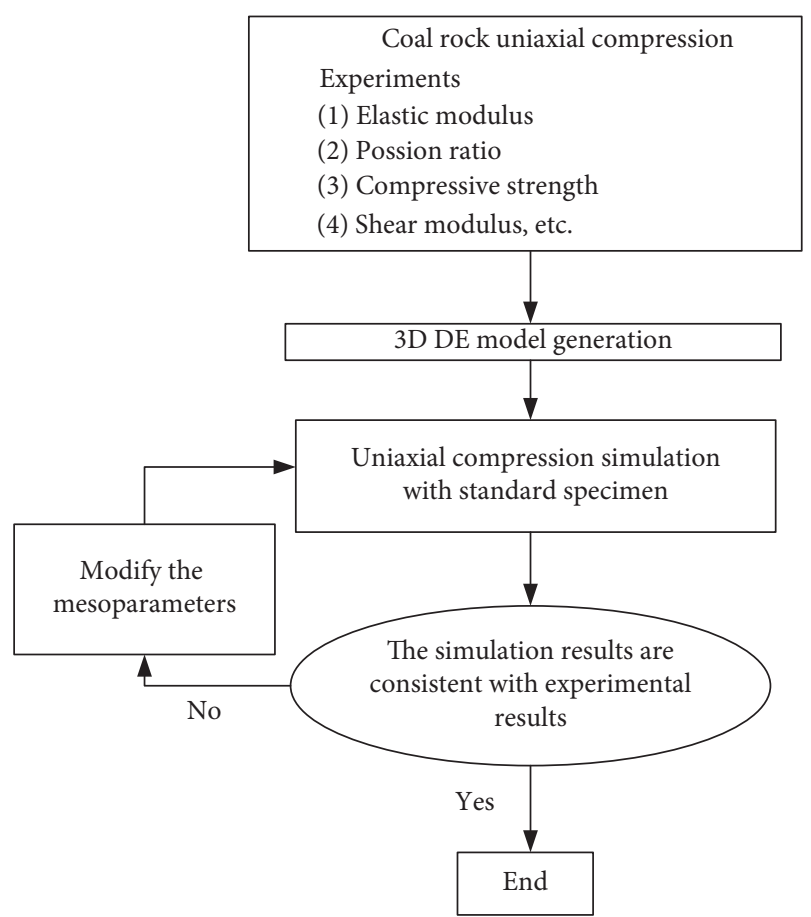

FIgURE 14: Calibration procedures for mesoparameters of HCR.
(1) Conduct uniaxial compressive experiments on the selected coal sample to determine the intrinsic material parameters, such as elastic modulus, shear modulus, Poisson's ratio, and compressive strength.

(2) Establish 3D DE models of HCR in PFC3D.

(3) Conduct uniaxial compression simulations on the $3 \mathrm{D}$ DE model of HCRs to determine the mesomechanical parameters.

(4) The calculated simulation and experimental parameters were compared, which aims to calibrate the mesoparameters of HCRs. If the simulation results were not consistent with the experimental parameters, a new numerical model should be created by modifying the mesoparameters until the simulation parameters were consistent with the experimental parameters.

With the assumed mesoparameters of the HCR, the DEM calculations provided the uniaxial compressive strength of $8.9 \mathrm{MPa}$, the compressive elastic modulus of $3.9 \mathrm{GPa}$, and Poisson ratio of 0.21 , similarly as in the standard uniaxial compression experiments of coal rocks $(\sigma=9.6 \mathrm{MPa}, E=4.2 \mathrm{GPa}$, and $\mu=0.23)$. The final mesoparameters of the simulation model are shown in Table 3. 
TABLe 3: Mesoparameters of the PBM used in the DE model.

\begin{tabular}{|c|c|c|c|c|}
\hline & Mesoparameters & Value & Mesoparameters & Value \\
\hline \multirow{5}{*}{ Coal } & Ball density $\rho_{c}\left(\mathrm{~kg} / \mathrm{m}^{3}\right)$ & 1540 & Ball stiffness ratio $\bar{k}_{n} / \bar{k}_{s}$ & 2.17 \\
\hline & Effective modulus $E^{*}(\mathrm{~Pa})$ & $2.3 e 9$ & Tensile strength $\bar{\sigma}_{c}(\mathrm{~Pa})$ & $7.90 e 6$ \\
\hline & Friction coefficient $f$ & 0.3 & Cohesion $\bar{c}(\mathrm{~Pa})$ & $3.95 e 6$ \\
\hline & Installation gap $g_{r}(\mathrm{~m})$ & $1 e-4$ & Friction angle $\bar{\varphi}\left({ }^{\circ}\right)$ & 28 \\
\hline & Radius multiplier $\bar{\lambda}$ & 1 & Normal damping ratio $\beta_{n}$ & 0.75 \\
\hline \multirow{5}{*}{ Gangue } & Ball density $\rho_{g}\left(\mathrm{~kg} / \mathrm{m}^{3}\right)$ & 2950 & Ball stiffness ratio $\bar{k}_{n} / \bar{k}_{s}$ & 2.582 \\
\hline & Effective modulus $E^{*}(\mathrm{~Pa})$ & $6.0 e 9$ & Tensile strength $\bar{\sigma}_{c}(\mathrm{~Pa})$ & $3.65 e 7$ \\
\hline & Friction coefficient $f$ & 0.3 & Cohesion $\bar{c}(\mathrm{~Pa})$ & $3.04 e 7$ \\
\hline & Installation gap $g_{r}(\mathrm{~m})$ & $1 e-4$ & Friction angle $\bar{\varphi}\left({ }^{\circ}\right)$ & 34 \\
\hline & Radius multiplier $\bar{\lambda}$ & 1 & Normal damping ratio $\beta_{n}$ & 0.75 \\
\hline \multirow{4}{*}{ Interfaces } & Effective modulus $E^{*}(\mathrm{~Pa})$ & $4.15 e 9$ & Tensile strength $\bar{\sigma}_{c}(\mathrm{~Pa})$ & $3.42 e 7$ \\
\hline & Friction coefficient $f$ & 0.3 & Cohesion $\bar{c}(\mathrm{~Pa})$ & $1.72 e 7$ \\
\hline & Installation gap $g_{r}(\mathrm{~m})$ & $1 e-4$ & Friction angle $\bar{\varphi}\left({ }^{\circ}\right)$ & 31 \\
\hline & Ball stiffness ratio $\bar{k}_{n} / \bar{k}_{s}$ & 2.38 & Normal damping ratio $\beta_{n}$ & 0.75 \\
\hline
\end{tabular}

4.2. Dynamic Impact Simulation. For the simulation, particle flow code in three dimensions (PFC3D) in version 5.0 [39] is selected to run the DE model under dynamic impact loads. Dynamic impact loading in positive $y$-axis directions are modelled to investigate the $3 \mathrm{D}$ mesostructure effects on the damage patterns and fracture mechanism under different impact velocities. The 3D DE model of HCR under positive $y$-load is shown in Figure 15. As shown in Figure 15, the top and bottom walls are created to apply the load in positive $y$ direction, where the desired impact velocity corresponding to a certain height $h$ is applied on the top wall and the bottom wall remains fixed, and lateral deformations are allowed freely. To describe the simulation results presented below, the time evolutions of the wall force generated at the HCRwall interface and the damage ratio [40-42] (i.e., the damage ratio of coal and gangue is defined as the ratio of the number of broken bonds and initial bonds in the coal phase and gangue phase, respectively) are selected as the two important parameters to quantitatively characterize failure patterns and load-carrying capacities.

The impact simulations for HCR have been used to examine how the breakage behaviors are affected by different impact velocities in positive $y$-load mode. It should be noted that the numerical simulation process was ended with the condition of the wall force reaching $60 \%$ of the maximum wall force. The wall forces for HCR as functions of the time in $y$-load under different impact velocities are shown in Figure 16 , with key loading points $(\mathrm{A} \sim \mathrm{D}$ (positive $y$-load)) marked at the curve of wall force under $8 \mathrm{~m} / \mathrm{s}$, respectively. As shown in Figure 16, the maximum wall forces of the HCR are calculated to be $69.01,69.37,82.33,87.43$, and $83.94 \mathrm{KN}$ in negative $y$-load with the impact velocities of $6,8,10,12$, and $14 \mathrm{~m} / \mathrm{s}$, respectively, with $17.78 \%$ maximum difference. The maximum wall force increased first then slightly decreased, which indicated that there exists an optimal impact velocity with best crushing effects but without excessive energy consumption. Figure 17 compares the damage ratio results of HCR and different mineral phases (coal and gangue, respectively) affected by positive $y$-load under different impact velocities. As shown in Figure 17, the damage ratios of the HCR and coal phase are much higher than the

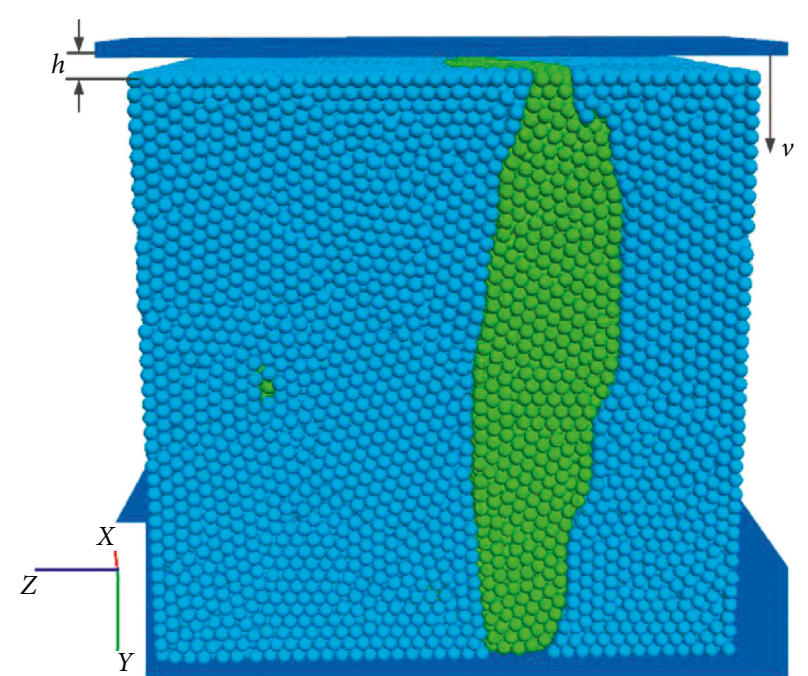

Figure 15: 3D DE model of HCR generation and in the positive $y$ load mode.

results of the gangue phase in positive $y$-load mode, which indicated that gangue phases are less damaged in the positive $y$-load mode.

The internal damage initiation state and evolution state of the HCR in positive $y$-load are shown in Figure 18. The four key loading points $(\mathrm{A} \sim \mathrm{D})$ in the positive $y$-load mode of the curves at $8 \mathrm{~m} / \mathrm{s}$ are selected to illustrate how the gangue interface affects initiation and propagation of damage bands. It should be noticed that the fragment color, which are determined by the built-in language FISH provided by PFC3D, mainly caused by the evolution state of HCR. As shown in Figure 18, only few percentage of fine debris is generated at the HCR-wall interface in loading point $\mathrm{A}$. The damage bands tend to propagate from the gangue interface to form several main fragments due to the relative movement between the HCR and the wall, which can be seen in the evolution states from the loading point $\mathrm{B}$ to $\mathrm{D}$. It is clear from the evolution images of the key points $A \sim D$ that the damage initiates mostly around the gangue interface, which leads to generation of several coal fragments mostly around 


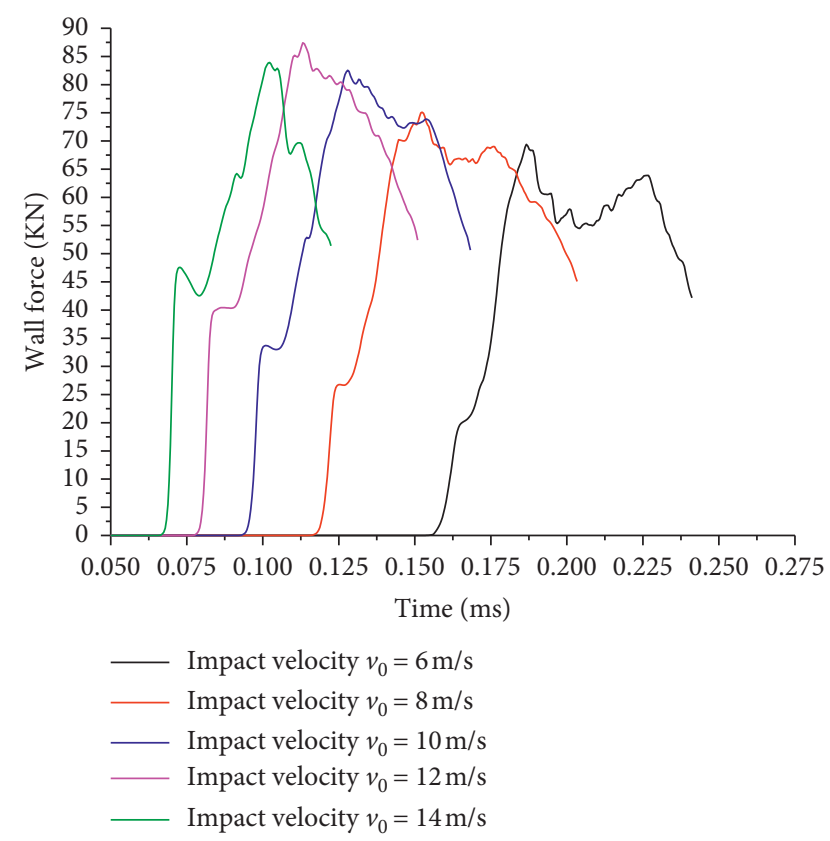

FIGURE 16: Wall forces for HCR as functions of the time in positive $y$-load modes under different impact velocities.

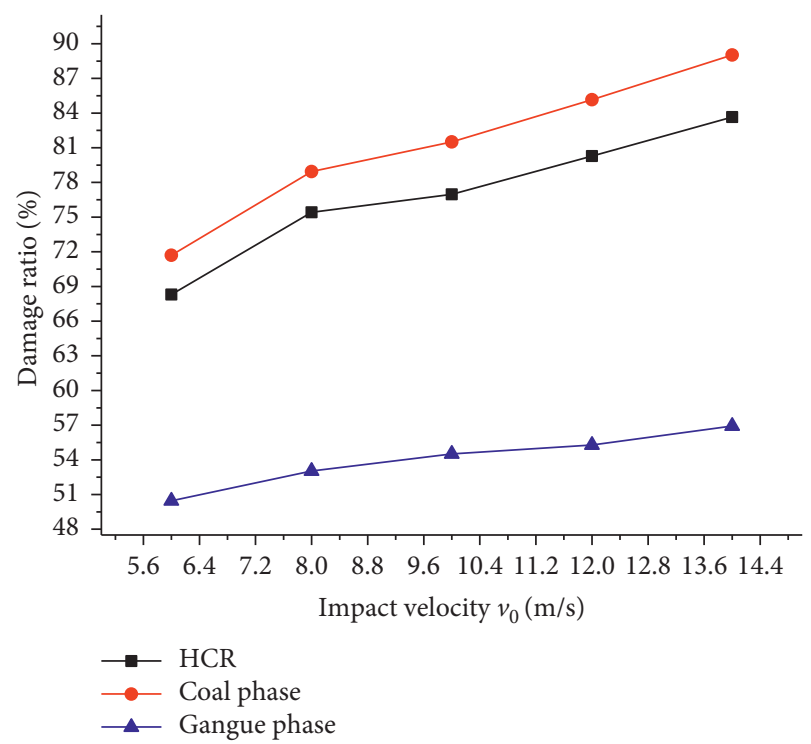

FIGURE 17: Variations of damage ratios of the HCR, coal phase, and gangue phase in the positive $y$-load mode under different impact velocities.

the gangue interface, and only the upper part of the gangue phase is changed to the failure state. It indicated that the damage bands tend to propagate along the gangue interface under the condition of the loading direction, which is almost perpendicular to the growth direction of the gangue interface.

\section{Conclusions}

This paper presents an application of milli- and micro-XCT to mesostructure characterization of individual CGPs and

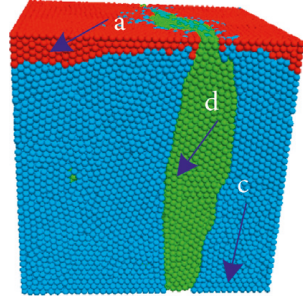

(a)

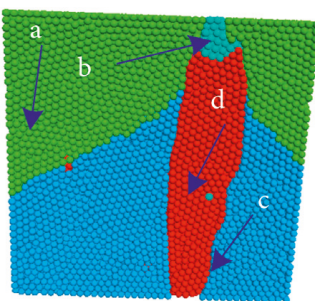

(c)

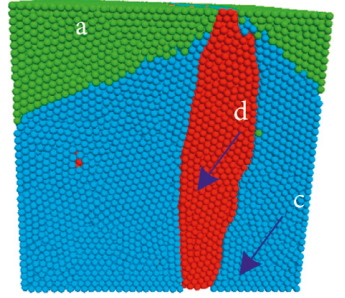

(b)

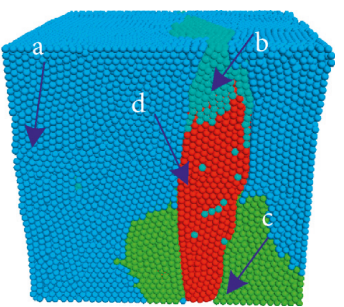

(d)
FIGURE 18: Damage initiation and evolution states under positive $y$ load at loading points $\mathrm{A} \sim \mathrm{D}$ (in this figure, $\mathrm{a}$ and $\mathrm{b}$ represent the failure zone of coal and gangue phases, respectively, $\mathrm{c}$ and $\mathrm{d}$ represent the undamaged zone of coal and gangue phases, respectively).

failure patterns analysis using dynamic impact simulations. A detailed study has been presented on the quantitative computational characterization of the mesostructure of individual CGPs, and the quantitative numerical simulation results are also showed as follows:

(1) The conventional threshold segmentation algorithm and the feature-based classification algorithm are proposed to identify particle boundaries and mineral phase boundaries of CGPs. It proved that the featurebased classification algorithm has good segmentation results of the small-scale CT image and the artificial CT image. The volume proportion distribution of internal composition and initial damage of individual CGPs can be determined through different XCT image analysis methods.

(2) Internal composition and 3D spatial distribution of mineral phases in individual particle can be characterized using XCT techniques. The mesomorphological parameters of individual particles are also carefully quantified using various image processing techniques. All the defined mesomorphological parameters of the individual CGPs, including the crack length, angle, width, and fracture ratio, present different distribution characteristics in the individual CGPs.

(3) The impact simulations for HCR have been used to examine how the breakage behaviors are affected by the 3D mesostructure under different impact velocities. Both the shape of the gangue phase and approximate location of interfaces are the key parameters that should be taken into account to study the evolution process of mesocracks from bridging into several main fragments. This study demonstrates 
that combining the milli- and micro-XCT tests and image-based DE modelling is an effective technique to investigate the internal damage and failure patterns in HCRs.

\section{Nomenclature}

$\rho_{c}: \quad$ The density of the coal phase $\left(\mathrm{kg} / \mathrm{m}^{3}\right)$

$\rho_{g}: \quad$ The density of the gangue phase $\left(\mathrm{kg} / \mathrm{m}^{3}\right)$

$E_{c}$ : The elastic modulus of the coal phase $(\mathrm{Pa})$

$E_{g}: \quad$ The elastic modulus of the gangue phase $(\mathrm{Pa})$

$v_{c}$ : Poisson's ratio of the coal phase

$v_{g}$ : Poisson's ratio of the gangue phase

$\frac{g}{R}: \quad$ The bond radius $(\mathrm{m})$

$\bar{\sigma}_{\max }:$ The maximum tensile stresses $(\mathrm{Pa})$

$\bar{\tau}_{\max }:$ The maximum shear stresses $(\mathrm{Pa})$

$\beta$ : $\quad$ The moment contribution factor

$\bar{k}_{n} / \bar{k}_{s}:$ Ball stiffness ratio

$\bar{\sigma}_{c}: \quad$ Tensile strength, $(\mathrm{Pa})$

$\bar{c}: \quad$ Cohesion $(\mathrm{Pa})$

$\bar{\varphi}: \quad$ Friction angle $\left({ }^{\circ}\right)$

$\beta_{n}$ : Normal damping ratio.

\section{Data Availability}

The data used to support the findings of this study are available from the corresponding author upon request.

\section{Conflicts of Interest}

The authors declare that there are no conflicts of interest regarding the publication of this paper.

\section{Acknowledgments}

The research was funded by the China Postdoctoral Science Foundation (2018M630676), National Nature Science Foundation of China (Nos. 51675521 and 51779224), Zhejiang Basic Public Welfare Research Program (No. LHZ19E090002), and Open Foundation of Shandong Province Key Laboratory of Mine Mechanical Engineering (No. 2019KLMM105).

\section{References}

[1] C. Bergins, J. Hulston, K. Strauss, and A. L. Chaffee, "Mechanical/thermal dewatering of lignite. Part 3: physical properties and pore structure of MTE product coals," Fuel, vol. 86, no. 1-2, pp. 3-16, 2007.

[2] D.-l. Yang, J.-p. Li, C.-l. Du, K.-h. Zheng, and S.-y. Liu, "Particle size distribution of coal and gangue after impactcrush separation," Journal of Central South University, vol. 24, no. 6, pp. 1252-1262, 2017.

[3] H. Tian, M. Ziegler, and T. Kempka, "Physical and mechanical behavior of claystone exposed to temperatures up to $1000^{\circ} \mathrm{C}$," International Journal of Rock Mechanics and Mining Sciences, vol. 70, pp. 144-153, 2014.

[4] J. Malaiskiene, R. Maciulaitis, and A. Kicaite, "Dependence of ceramics physical-mechanical properties on chemical and mineralogical composition," Construction and Building Materials, vol. 25, no. 8, pp. 3168-3174, 2011.
[5] A. R. Videla, C. L. Lin, and J. D. Miller, "3D characterization of individual multiphase particles in packed particle beds by X-ray microtomography (XMT)," International Journal of Mineral Processing, vol. 84, no. 1-4, pp. 321-326, 2007.

[6] W. Ren, Z. Yang, R. Sharma, C. Zhang, and P. J. Withers, "Two-dimensional X-ray CT image based meso-scale fracture modelling of concrete," Engineering Fracture Mechanics, vol. 133, pp. 24-39, 2015.

[7] W. Ren, Z. Yang, R. Sharma, S. A. McDonald, and P. M. Mummery, "Three-dimensional in situ XCT characterization and FE modelling of cracking in concrete," Complexity, vol. 2018, Article ID 3856584, 11 pages, 2018.

[8] J. Hu, P. Liu, D. Wang, M. Oeser, and Y. Tan, "Investigation on fatigue damage of asphalt mixture with different air-voids using microstructural analysis," Construction and Building Materials, vol. 125, pp. 936-945, 2016.

[9] J. Hu, P. Liu, and B. Steinauer, "A study on fatigue damage of asphalt mixture under different compaction using 3D-microstructural characteristics," Frontiers of Structural and Civil Engineering, vol. 11, no. 3, pp. 329-337, 2017.

[10] R. Dann, M. Turner, M. Close, and M. Knackstedt, "Multi-scale characterisation of coastal sand aquifer media for contaminant transport using X-ray computed tomography," Environmental Earth Sciences, vol. 63, no. 5, pp. 1125-1137, 2011.

[11] J. Knackstedt, E. Vargas, and E. Barroso, "Studies of mechanisms associated with sand production using X ray CT scan," in Advances in X-Ray Tomography for Geomaterials, pp. 199-205, John Wiley \& Sons, Hoboken, NJ, USA, 2010.

[12] P. Kodali, N. Dhawan, T. Depci, C. L. Lin, and J. D. Miller, "Particle damage and exposure analysis in HPGR crushing of selected copper ores for column leaching," Minerals Engineering, vol. 24, no. 13, pp. 1478-1487, 2011.

[13] L. C. Bam, J. A. Miller, M. F. Becker et al., "X-ray computed tomography-determination of rapid scanning parameters for geo-metallurgical analysis of iron ore," in Proceedings of the Third AusIMM International Geo-metallurgy Conference, pp. 209-220, Perth, Australia, June 2016.

[14] K. Hiraki, Y. Yamazaki, T. Kanai et al., "Numerical analysis of 3-D microstructure of coke using micro X-ray CT," ISIJ International, vol. 52, no. 11, pp. 1966-1972, 2012.

[15] F. Demir, "Prediction of elastic modulus of normal and high strength concrete by artificial neural networks," Construction and Building Materials, vol. 22, no. 7, pp. 1428-1435, 2008.

[16] H. Wang and Q. Li, "Prediction of elastic modulus and Poisson's ratio for unsaturated concrete," International Journal of Solids and Structures, vol. 44, no. 5, pp. 1370-1379, 2007.

[17] B. Ahmadi-Nedushan, "Prediction of elastic modulus of normal and high strength concrete using ANFIS and optimal nonlinear regression models," Construction and Building Materials, vol. 36, no. 6, pp. 665-673, 2012.

[18] V. Cnudde and M. N. Boone, "High-resolution X-ray computed tomography in geosciences: a review of the current technology and applications," Earth-Science Reviews, vol. 123, pp. 1-17, 2013.

[19] D. Wildenschild and A. P. Sheppard, "X-ray imaging and analysis techniques for quantifying pore-scale structure and processes in subsurface porous medium systems," Advances in Water Resources, vol. 51, pp. 217-246, 2013.

[20] L. M. Pant, H. Huang, M. Secanell, S. Larter, and S. K. Mitra, "Multi scale characterization of coal structure for mass transport," Fuel, vol. 159, pp. 315-323, 2015.

[21] J. D. Miller, C. L. Lin, C. Garcia, and H. Arias, "Ultimate recovery in heap leaching operations as established from 
mineral exposure analysis by X-ray microtomography," International Journal of Mineral Processing, vol. 72, no. 1-4, pp. 331-340, 2003.

[22] C. L. Arias and J. D. Miller, "3D characterization and analysis of particle shape using X-ray microtomography (XMT)," Powder Technology, vol. 154, no. 1, pp. 61-69, 2005.

[23] A. Videla, C.-L. Lin, and J. D. Miller, "Watershed functions applied to a $3 \mathrm{D}$ image segmentation problem for the analysis of packed particle beds," Particle \& Particle Systems Characterization, vol. 23, no. 3-4, pp. 237-245, 2006.

[24] C. L. Lin and J. D. Miller, "Cone beam X-ray microtomography-a new facility for three-dimensional analysis of multiphase materials," Mining, Metallurgy \& Exploration, vol. 19, no. 2, pp. 65-71, 2002.

[25] C. L. Lin, J. D. Miller, and G. H. Luttrell, "Evaluation of a CTbased coal washability analysis system under simulated online conditions," Mining, Metallurgy \& Exploration, vol. 19, no. 1, pp. 9-16, 2002.

[26] C. L. Lin, J. D. Miller, and C. H. Hsieh, "Particle damage during HPGR breakage as described by specific surface area distribution of cracks in the crushed products," in Proceedings of the International Mineral Processing Congress 2012: Innovative Processing for Sustainable Growth, pp. 3397-3410, New Delhi, India, 2012.

[27] R. A. Ketcham, "Three-dimensional grain fabric measurements using high-resolution X-ray computed tomography," Journal of Structural Geology, vol. 27, no. 7, pp. 1217-1228, 2005.

[28] Y. Wang, C. L. Lin, and J. D. Miller, "Improved 3D image segmentation for X-ray tomographic analysis of packed particle beds," Minerals Engineering, vol. 83, no. 8, pp. 185191, 2015.

[29] I. Arganda-Carreras, V. Kaynig, C. Rueden et al., "Trainable weka segmentation: a machine learning tool for microscopy pixel classification," Bioinformatics, vol. 33, no. 15, pp. 2424-2426, 2017.

[30] M. Taguchi, S. Hirokawa, I. Yasuda, K. Tokuda, and Y. Adachi, "Microstructure detection by advanced image processing," Tetsu-to-Hagane, vol. 103, no. 3, pp. 142-148, 2017.

[31] C. Wang, A. Sha, and Z. Sun, "Pavement crack classification based on chain code," in Proceedings of the Seventh International Conference on Fuzzy Systems and Knowledge Discovery, pp. 593-597, IEEE, Shandong, China, August 2010.

[32] Z. Qu, Y. Guo, F.-R. Ju, L. Liu, and L.-D. Lin, "The algorithm of accelerated cracks detection and extracting skeleton by direction chain code in concrete surface image," The Imaging Science Journal, vol. 64, no. 3, pp. 119-130, 2016.

[33] W. S. Rasband, ImageJ: Image Processing and Analysis in Java, Astrophysics Source Code Library, Record ascl 1206.013, 2012.

[34] H. Jia and S. Ma, "The application of 3-D discontinuity network modeling in geotechnical engineering," International Journal of Rock Mechanics and Mining Sciences, vol. 41, no. 3, pp. 515-520, 2004.

[35] E. Béchet, J.-C. Cuilliere, and F. Trochu, "Generation of a finite element MESH from stereolithography (STL) files," Computer-Aided Design, vol. 34, no. 1, pp. 1-17, 2002.

[36] M. D. Berg, Computational Geometry: Algorithms and Applications, Springer, Berlin, Germany, 2000.

[37] K. Zheng, C. Du, J. Li, B. Qiu, L. Fu, and J. Dong, "Numerical simulation of the impact-breakage behavior of non-spherical agglomerates," Powder Technology, vol. 286, pp. 582-591, 2015.
[38] K. Zheng, B. Qiu, Z. Wang, J. Li, and K. Gao, "Modelling heterogeneous coal-rock (HCR) failure patterns under dynamic impact loads using image-based finite element (FE) and discrete element (DE) model," Powder Technology, 2019.

[39] Itasca Consulting Group, Inc., PFC3D, Particle Flow Code in 3 Dimensions, User's Guide, Itasca Consulting Group, Inc., Minneapolis, MN, USA, 2008, https://www.itascacg.com.

[40] K. D. Kafui and C. Thornton, "Numerical simulations of impact breakage of a spherical crystalline agglomerate," Powder Technology, vol. 109, no. 1-3, pp. 113-132, 2000.

[41] C. Thornton and L. Liu, "How do agglomerates break?," Powder Technology, vol. 143-144, no. 26, pp. 110-116, 2004.

[42] B. K. Mishra and C. Thornton, "Impact breakage of particle agglomerates," International Journal of Mineral Processing, vol. 61, no. 4, pp. 225-239, 2001. 


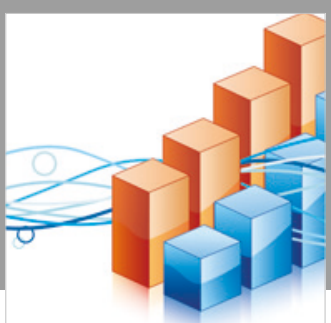

Advances in

Operations Research

\section{-n-m}
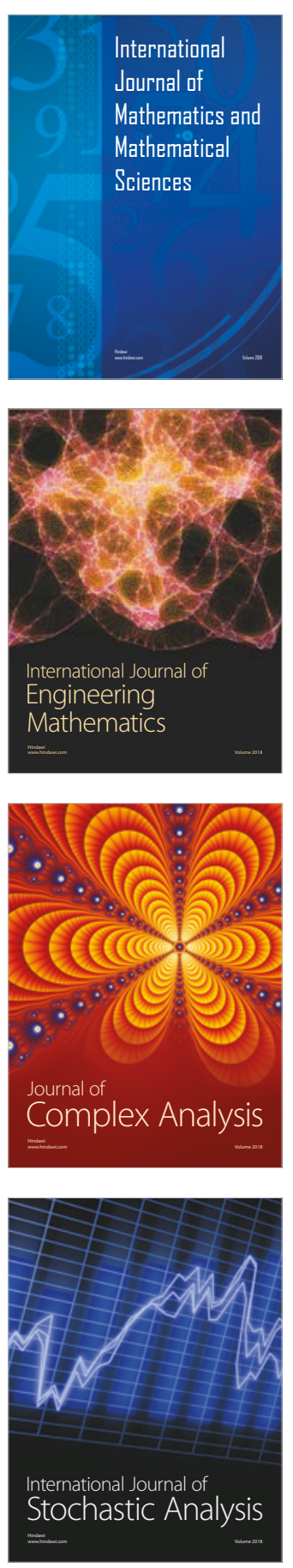
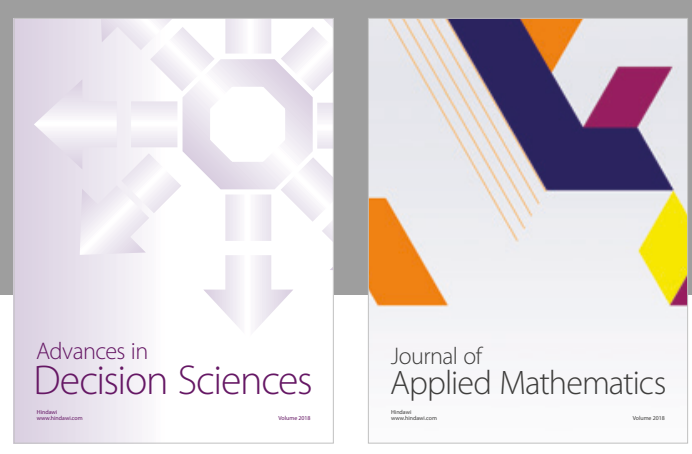

Journal of

Applied Mathematics
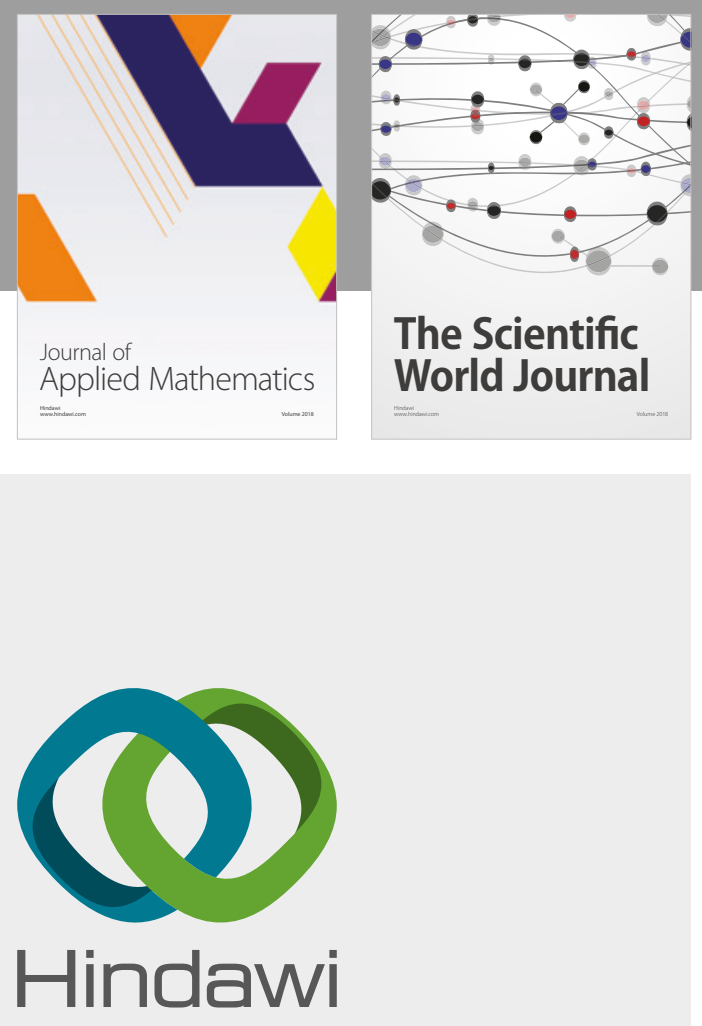

Submit your manuscripts at

www.hindawi.com

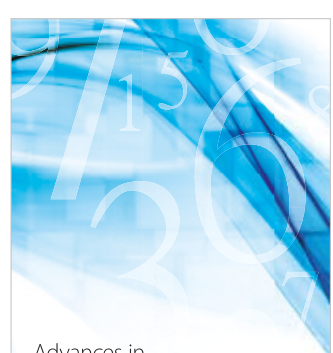

Advances in
Numerical Analysis
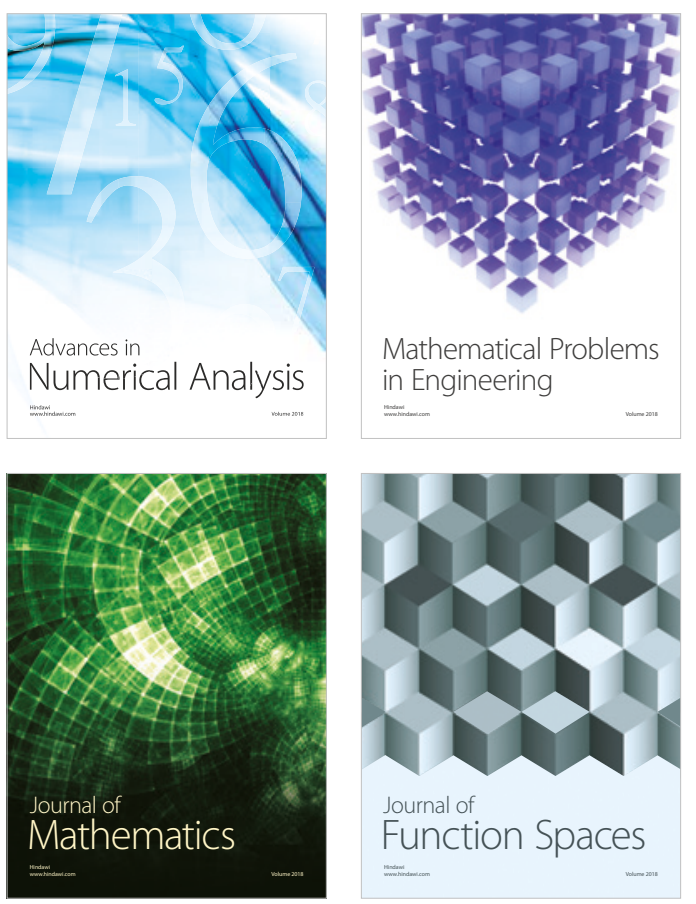

Mathematical Problems in Engineering

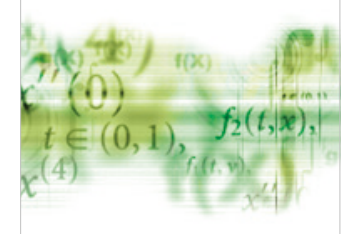

International Journal of

Differential Equations

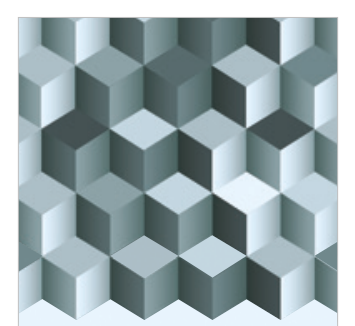

Journal of

Function Spaces
The Scientific

World Journal

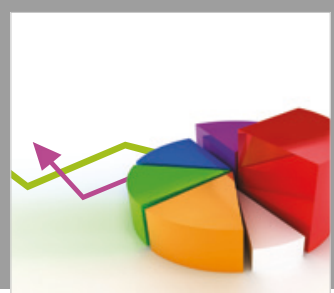

Journal of

Probability and Statistics
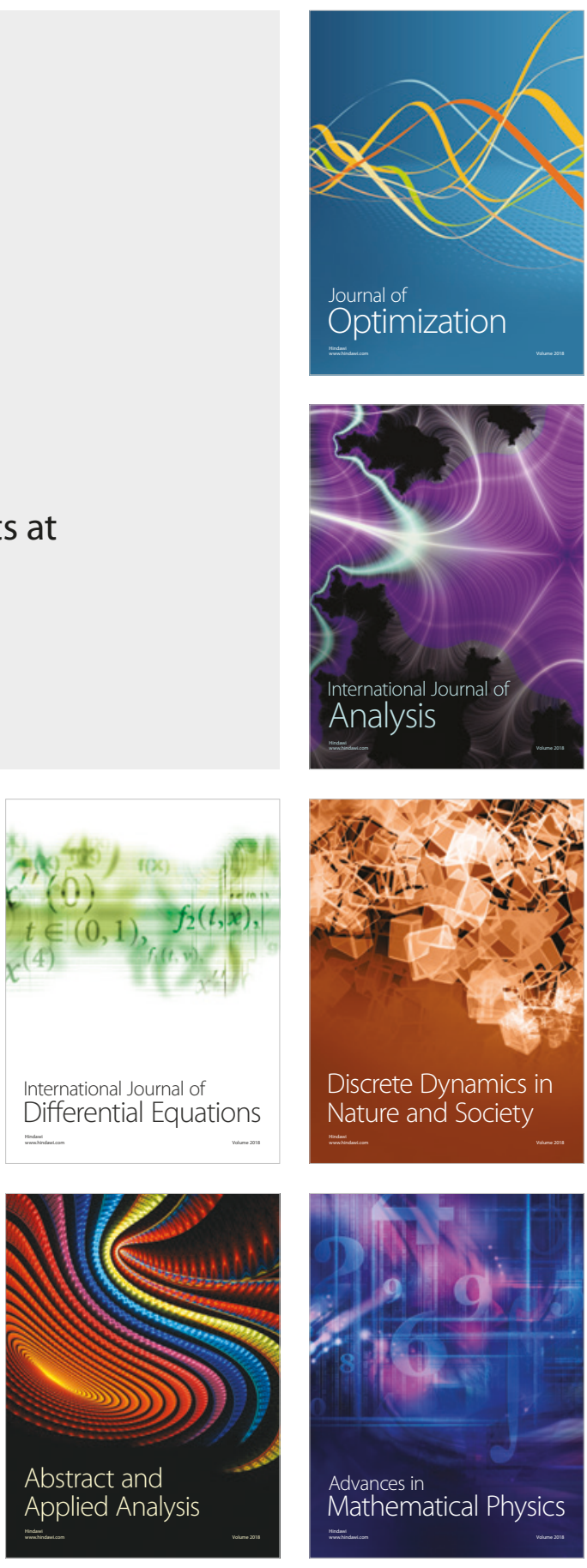